\title{
Compliment Response in Teacher-Student Interaction: Examples from ICT Platforms
}

\author{
Fan Yang, Shuyan He, Linyi Qi, and Jing Wen
}

\begin{abstract}
The recent development of Information and Communication Technology (ICT) allows online platforms including Moodle to be applied in education. This paper, having looking through research on compliment responses from different perspectives, intends to conduct an empirical research to explore patterns and functions of teacher-student compliment response in ICT platforms of an English course in a Chinese Research University. The findings of this study suggest that in ICT platform setting, Chinese EFL students tend to choose agreement strategy when responding to teachers' compliments, and that teachers tend to use compliments as approval of students' work. The research also indicates that ICT platforms might help facilitate meaningful teacher-student interaction after class, thus making language education more motivating and engaging.
\end{abstract}

Index Terms-Information and communication technology, compliment response, second language education.

\section{INTRODUCTION}

The recent advance in information and communication technology (ICT) helps to facilitate teacher-student interaction research, as instructor-learner interaction nowadays can happen in and out of classrooms, in both written and oral forms. Despite the forms and areas, the success of this interaction is often regulated by politeness in language use, and one of the most frequently mentioned issues in politeness studies is compliment and compliment response.

The purpose of this study is to explore patterns and functions of compliment response (CR) in teacher-student interactions in an intercultural academic setting. Guided by Brown and Levinson's [1] politeness theory, the study tries to identify CR acts of Chinese English as Foreign Language (EFL) students with teachers in educational platforms. With gathered data, this study will try to interpret and explore the possible pragmatic implications of those compliment response acts, and then, a synthesized conclusion as well as its application for L2 teaching will be summarized. It is hoped that the findings of this research can make both theoretical and practical contributions, as it tries to offer second language teachers and researchers the opportunity to better understand EFL learners' intercultural needs theoretically, and also provides empirical instructor-student compliment response samples in ICT platforms.

Manuscript received December 10, 2019; revised February 23, 2020

Fan Yang, Shuyan He, Linyi Qi, and Jing Wen are with University of Electronic Science and Technology of China, 611731, Chengdu, China (e-mail: yangfan9207@uestc.edu.cn,_heshuyan@uestc.edu.cn, qilinyi@uestc.edu.cn, joanniewen@uestc.edu.cn).

\section{THEORETICAL BACKDROP}

\section{A. Positions and Functions}

Compliment is a speech act that caters to positive face wants from politeness perspective [2]. Positive face, proposed in Brown and Levinson's politeness theory, is "the positive consistent self-image or 'personality' (crucially including the desire that this self-image be appreciated and approved of) claimed by interactions" [1].

The present compliment related studies are mostly influenced by Manes and Wolfson, whose studies in American English [2]-[4] showed that compliment is done through formularic utterances. In syntactic scale, compliments are confined to a certain set of structures, for example, in English, the NP is/sounds (really) Adj type (e.g., "Your hat is cool!") and the I (really) like/love NP type (e.g., I like your coat!") are the most popular compliment types. In lexical scale, words used in compliments are mostly adjectives like good, cute, beautiful, and nice and verbs like love and like. In addition, compliment might have different functions for different purposes, as is summarized in the following Table I [5].

TABLE I: FUNCTIONS OF COMPLIMENTS

1. To express admiration or approval of someone's work/appearance/taste

2. To establish/confirm/maintain solidarity

3. To replace gratitude/greetings/congratulations/apologies

4. To soften a face-threatening act such as apologies, requests and criticisms

5. To open and sustain conversation

6. To reinforce desired behaviour

In terms of interlocutors, compliments occurred between people of equal status (casual friends, acquaintances and colleges) and also unequal status (teacher-student). These findings were later proved in Herbert's [6]-[8] work and had since been used in the research on compliment in other languages and cultures.

Studies on CR started with Pomerantz's pioneering research in 1978. Pomerantz [9] proposed two conflicting constraints in CR behaviors: 1) agree with the complimenter; 2) avoid self-praise. The first constraint explains compliment acceptance, represented by appreciation tokens like "Thank you!", the second constraint explains the downgrade of the compliment or transfer of credit, like the response to compliment "Your coat looks pretty nice!" "It keeps me warm" or "It is my birthday present". The two constraints, as Pomerantz herself pointed out, could find support from Leech's Politeness Principle [10] in politeness research. In Politeness Principle, Leech posits six interpersonal maxims guiding people's politeness strategy 
usage. Here, Pomerantz's first constraint coincides with the Agreement Maxim, the second constraint coincides with the Modesty Maxim in Politeness Principle, for Agreement Maxim states "to minimize disagreement between yourself and others; maximize agreement between yourself and others", and Modesty Maxim states "to minimize self-praise; maximize self-dispraise". Therefore, the intricate interplay between the two maxims and constraints makes the art of CR delicate.

\section{B. Patterns of Compliment Response: Chinese vs English Language}

By definition, compliment is the linguistic act that serves to satisfy the positive face wants of someone and response to a compliment should naturally be polite, too. However, what is considered to be polite might vary from culture to culture, and also language to language. It is also pointed out that in many languages, complimentary language frequently appears in greeting, thanking, apologizing, opening a conversation for compliment stands for encouragement and reinforcing the solidarity of interpersonal relationships [6].

In the English language, $\mathrm{CR}$ is summarized to be mainly of three types: Agreement, non-agreement and other interpretations [6], each of them includes several sub-categories (Table II).

TABLE II: RESPONSE TYPE

\begin{tabular}{|c|c|}
\hline Category: & Sample: \\
\hline \multicolumn{2}{|l|}{ 1. Agreement } \\
\hline \multicolumn{2}{|l|}{ 1.1 Acceptance } \\
\hline 1.1.1 Appreciation token & Thank you \\
\hline 1.1.2 Comment & Yeah, it's my favorite too \\
\hline \multicolumn{2}{|l|}{ 1.2 Non-Acceptance } \\
\hline 1.2.1 History & $\begin{array}{l}\text { Really brings out the blue in } \\
\text { my eyes, doesn't it? }\end{array}$ \\
\hline \multicolumn{2}{|l|}{ 1.2.2 Transfer } \\
\hline 1.2.2.1 Reassign & My brother gave it to me \\
\hline 1.2.2.2 Return & So is yours \\
\hline \multicolumn{2}{|l|}{ 2. Non-Agreement } \\
\hline \multicolumn{2}{|l|}{ 2.1 Acknowledgement } \\
\hline 2.1.1 Question & Do you really think so? \\
\hline 2.1.2 Scale Down & It's really quite old \\
\hline 2.1.3 Disagreement & I hate it \\
\hline 2.1.4 Qualification & It's alright, but Len's is nicer \\
\hline 2.2 No Acknowledgement & No response \\
\hline
\end{tabular}

This summary is supported by massive empirical studies, with the most famous one conducted in academic contexts, where $1062 \mathrm{CR}$ tokens were gathered through questionnaires and discourse completion tests from participants in an American University [8]. Results showed that $36.65 \%$ instances fell into the agreement category, $9.98 \%$ instances fell into the non-agreement category, and the rest fell into the other interpretations category.

This taxonomy was then used by several similar studies conducted in other contexts (workplace company and hospital), where similar results were revealed [11], even the one which collected its data from forty typical American films so as to gain authentic and naturally-occurring data source [12]. Thus these studies lead to the conclusion that not to reject category and Agreement Maxims suit the Americans politeness strategy in CR best, and Herbert [7] even quoted from an etiquette book saying that "when you are complimented, the only response necessary is "Thank you" and "A simple thank you is sufficient" [13] to prove that virtually for all American English speakers, the correct
$\mathrm{CR}$ is acceptance and "thank you".

In Chinese language, compliment response is found to be of a different displaying form [14], [15]. Although highly valued in Chinese cultures, many researchers proposed that $\mathrm{CR}$ is often combined with traditional Chinese modest and reserved cultural norms. What is more, by analyzing Leech's maxim theory, these researchers suggested that Chinese style of polite CR suits the Modesty Maxim best. All these discussions lead to the hypothesis that Chinese CR, different from English, would be reserved and modest.

As is shown in the following Table III, a large number of empirical studies were conducted to testify this hypothesis, covering population from Mainland, Taiwanese Chinese, to Chinese immigrants, with academic contexts being the major background. All of these research findings support the specific Chinese Modesty Maxim approach of CR hypotheses. However, these studies although reveal a tendency in changing proportion of accepting the compliments, with detailed acceptance proportion growing from $1 \%$ to $49 \%$, possibly influenced by regional differences and increasing number of EFL learners [16]-[18].

TABLE III: CHINESE COMPLIMENT ACCEPTANCE AND REJECTION

\begin{tabular}{l|l|l}
\hline Subjects & Acceptance & Rejection \\
\hline Mainland Chinese (Xi'an) [19] & 1.03 & 95 \\
Mainland Chinese [20] & 20 & 80 \\
Hong Kong Chinese in Britain [21] & 41 & 22 \\
DCT Mainland Chinese (Kunming) [22] & 7 & 28.93 \\
Natural Mainland Chinese (Kunming) & & \\
[23] & 15.63 & 33.98 \\
Taiwanese Chinese [24] & 13 & 24 \\
Chinese in Australia [14] & 49 & 38 \\
\hline
\end{tabular}

In addition, these studies also pointed out that the huge difference in Chinese and English CR is causing embarrassment and possible conversational failure in both academic and non-academic contexts for Chinese EFL learners.

With review of previous literature, this study intends to conduct its $\mathrm{CR}$ research in an intercultural academic context: a transnational higher education institution where Chinese EFL learners, native and non-native English teachers communicate through Moodle, an online educational platform. The research questions investigated are:

1) What are the patterns of compliment response in the platforms?

2) What are the functions of the compliments?

3) Are the compliments and compliment responses in the platforms helpful for teacher-student interaction?

\section{Methodology}

\section{A. Sources of Data}

For the purpose of this study, one open English course on the online educational platform Moodle, as well as the course group formed in Chinese ICT platforms including QQ and We-chat, were chosen as the main sources for extracting compliment and compliment response tokens. 8 native speaker teachers ( 2 based in Britain, 6 based in China), 23 non-native speaker teachers(all based in China) and 540 students are enrolled on Moodle in this course, and interactions between teacher to teacher, teacher to student 
happen on a daily basis on Moodle or relevant platforms. Included in this study were 56 English CR tokens of Chinese EFL learners. Excluded in this study were CR tokens that might be interpreted into different meanings. Here it should also be noticed that in some conversations, emotion icons are used by the respondents as a simple and clear way to express feelings in CR and these emotion icons are included as data.

\section{B. Interviews}

Interviews were also conducted to investigate on the attitude of teachers and students towards CR in the platform. 1 native speaker teacher and 1 non-native speaker teacher based in China, as well as 18 students were interviewed. During the interview, the researcher read the CR tokens and the relevant platform chatting records together with the participant. The participants were invited to reflect on their thinking process when and after responding to the compliment. These interviews serve as a supplement support for the verbal analysis of the pragmatic functions of CR.

\section{FINDINGS}

\section{A. Patterns of Compliment Response}

As is shown in the following Table IV, in the main categories, agreement responses $(52.8 \%)$ are slightly more frequent in relevant conversations compared with non-agreement responses (48.2\%). The majority of agreement responses fall into acceptance (22 out of 29), especially the direct thank you type (16 out of 22 ); for non-acceptance, all instances belong to the reassign type--transferring the credit to someone else. Two thirds of the non-agreement type of responses are no acknowledgement, while in the acknowledgement type, scale down is the most popular (7 out of 9).

TABLE IV: RESPONSE PATTERNS

\begin{tabular}{c|l|l}
\hline & Number & Percentage \\
\hline 1. Agreement & 29 & $52.8 \%$ \\
\hline 1.1 Acceptance & 22 & $39.3 \%$ \\
1.1.1 Appreciation token & 16 & $28.6 \%$ \\
1.1.2 Comment & 6 & $10.7 \%$ \\
1.2 Non-Acceptance & 7 & $12.5 \%$ \\
1.2.1 History & 0 & $0 \%$ \\
1.2.2 Transfer & 7 & $12.5 \%$ \\
1.2.2.1 Reassign & 7 & $12.5 \%$ \\
1.2.2.2 Return & 0 & $0 \%$ \\
\hline 2. Non-Agreement & 27 & $48.2 \%$ \\
\hline 2.1 Acknowledgement & 9 & $16.1 \%$ \\
2.1.1 Question & 1 & $1.8 \%$ \\
2.1.2 Scale Down & 7 & $12.5 \%$ \\
2.1.3 Disagreement & 0 & $0 \%$ \\
2.1.4 Qualification & 1 & $1.8 \%$ \\
2.2 No Acknowledgement & 18 & $32.1 \%$ \\
\hline
\end{tabular}

The result contradicts with the mainstream opinion that Chinese people tend to employ non-agreement strategy in $\mathrm{CR}$. One possible reason to explain this phenomenon might be that the compliment responses are in English contexts. When EFL learners are communicating in English, they might obey the targeted language patterns when responding to compliments. In addition, Internet as the conversation context also allows those EFL learners more time to organize their linguistic responses in a seemingly more suitable way in compliment exchanges, thus reducing their spontaneous strategic reliance on mother tongue. This might also explain the frequent "no acknowledgement" responses in the data, as Internet helped the compliment recipients avoid encountering the face to face compliment exchanges, so they chose silence when they do not need to give impromptu responses.

Another interesting fact worth noticing is the compliment recipients' frequent usage of emotion icons. Popular emotion icons included "flower" icon meaning "thank you" in appreciation token strategy, and "shy face" "just so so" icon indicating the feeling of being flattered in scale down strategy. Compared with typing words, choosing emotion icons might be more time-saving in online communications, which probably explains its popularity. However, whether those icons can fully explain the recipients' feelings might still be questionable.

\section{B. Functions of the Compliments}

As is summarized in the following Table $\mathrm{V}$, the first function-expressing admiration and approval is the most popular, accounting for more than four fifths of the CR samples, while the third (replace gratitude), fifth (open conversation), and sixth (reinforce desired behavior) functions are not evident. Establishing solidarity and softening a face-threatening act then occupied the rest proportion.

\begin{tabular}{lll}
\multicolumn{4}{c}{ TABLE V: FunCTIONS OF COMPLIMENTS } \\
\hline $\begin{array}{l}\text { Number } \\
\text { 1. To express admiration or approval of } \\
\text { someone's work/appearance/taste }\end{array}$ & 46 & $82.1 \%$ \\
\hline 2. To establish/confirm/maintain solidarity & 6 & $10.7 \%$ \\
\hline $\begin{array}{l}\text { 3. To replace gratitude /greetings } \\
\text { /congratulations /apologies }\end{array}$ & 0 & $0 \%$ \\
\hline $\begin{array}{l}\text { 4. To soften a face-threatening act such as } \\
\text { apologies, requests and criticisms }\end{array}$ & 4 & $7.1 \%$ \\
\hline 5. To open and sustain conversation & 0 & $0 \%$ \\
\hline 6. To reinforce desired behavior & 0 & $0 \%$ \\
\hline
\end{tabular}

The result shows that similar to non-academic contexts [5], in academic contexts, the majority of compliments might be those expressing approval (or admiration) of others' work. In other words, teachers tended to make more compliments on individual student's work or improvement. The second most favored type of compliments might be maintaining solidarity, with typical phrase of "Well done! Everyone!", and these were used by teachers to build whole class rapport. Softening a face-threatening act was the function of the rest compliments, employed by teachers when they tried to ease the atmosphere before providing negative feedback to students.

\section{Efficiency of Compliment Response}

Both teachers and students mentioned in the interviews that they considered compliment exchange a necessary part in academic communication. Students reported that they felt "encouraged when receiving compliments from teachers". In addition, several students mentioned the establishment of "stronger inter-personal relationship bond with teachers" when they were able to make suitable compliment responses online.

The native and non-native speaker teachers stated that 
compliments are helpful tools for them to "motivate students" and "build teacher-student rapport". These teachers also suggested that compliment exchanges would be particularly helpful when students were engaged by responding to the compliments, which could further "facilitate teacher-student interaction". In a word, both teachers and students agreed that compliment response is a helpful for promoting teacher-student interaction.

\section{IMPLICATION}

Above review and discussion proved that since current development of ICT has allowed more intensive communication between teachers and students, it has also brought wider research area for relevant scholars, posting several research questions in related fields: Are there any differences between online and off-line compliment exchanges in teacher-student interaction? If so, how? Frequency or content? What could be done to facilitate more meaningful teacher-teacher, teacher-student, and student-student compliment exchanges with the help of ICT platforms? All of these are areas waiting for further investigation and cooperation by scholars from ICT and language education fields.

Apart from the theoretical implication, this study also implies that a more detailed instructional curriculum for ICT assisted language education is necessary. For language teachers, more meaningful attempts of teacher-student interaction in ICT platforms should be encouraged. For students, suitable intercultural education including compliment and compliment response strategies should be offered. For schools, more systematic instruction on the usage of ICT related skill and pedagogy training should be planed.

\section{CONCLUSION}

Before ICT was introduced into language education, teacher-student interaction seemed more of a pedagogical term and phenomenon in classroom teaching. However, current research has shown that ICT platforms have helped to facilitate meaningful teacher-student interaction after class, thus making language education more motivating and engaging. As above review and discussion have illustrated, ICT can offer a helping hand in language education both theoretically and practically. In addition, the discussion also reminds current researchers that more attention and efforts should be paid to ICT assisted language education, and that teachers should also be encouraged to make more meaningful teaching related practices on ICT platforms.

\section{CONFLICT OF INTEREST}

The authors declare no conflict of interest.

\section{AUTHOR CONTRIBUTIONS}

All authors made contributions to all aspects of this paper.

\section{ACKNOWLEDGMENT}

This work was supported by Glasgow College, University of Electronic Science and Technology of China. We thank our colleagues in Glasgow College, UESTC, and also the Dean Professor Zeng, the Deputy Dean Professor Liu, Secretary Mr. Gao, and Deputy Secretary Ms. He for their kind help.

\section{REFERENCES}

[1] B. Penelope and S. C. Levinson, "Universals in language usage: Politeness phenomena," in Questions and Politeness: Strategies in Social Interaction, Cambridge University Press, 1978, pp. 56-311.

[2] N. Wolfson, "An empirically based analysis of complimenting in American English. Sociolinguistics and language acquisition, 82-95. M. Kirch, At what age elementary school language teaching?' Modern Language Journal, vol. 40, pp. 399-400, 1983.

[3] J. Manes, "Compliments: A mirror of cultural values," Sociolinguistics and Language Acquisition, vol. 96, p. 102, 1983.

[4] J. Manes and N. Wolfson, The Compliment Formula. Conversational Routine: Explorations in Standardized Communication Situations and Prepatterned Speech, pp. 115-132, 1981.

[5] S. Y. A. M. Yusof and T. B. Hoon, "Compliments and compliment responses on Twitter among male and female celebrities," Pertanika Journal of Social Sciences and Humanities, vol. 22, pp. 75-96, 2014.

[6] R. K. Herbert, "Say thank you-or something," American Speech, vol. 61, no. 1, pp. 76-88, 1986 .

[7] R. K. Herbert, "The ethnography of English compliments and compliment responses: A contrastive sketch," Contrastive Pragmatics, pp. 3-35, 1989

[8] R. K. Herbert, "Sex-based differences in compliment behavior," Language in Society, vol. 19, no. 2, pp. 201-224, 1990.

[9] A. Pomerantz, "Compliment responses: Notes on the co-operation of multiple constraints," Studies in the Organization of Conversational Interaction, vol. 7, p. 112, 1978.

[10] G. Leech, Principles of Politeness, London and New York: Longman, 1983.

[11] A. Golato, Compliments and Compliment Responses: Grammatical Structure and Sequential Organization (Vol. 15), John Benjamins Publishing, 2005.

[12] K. R. Rose, "Compliments and compliment responses in film: Implications for pragmatics research and language teaching," IRAL, vol. 39, no. 4, pp. 309-326, 2001.

[13] D. Johnson, Entertaining and Etiquette for Today, Washington, DC: Acropolis, 1979.

[14] C. H. Tang and G. Q. Zhang, "A contrastive study of compliment responses among Australian English and Mandarin Chinese speakers," Journal of Pragmatics, vol. 41, no. 2, pp. 325-345, 2009.

[15] R. Chen and D. Yang, "Responding to compliments in Chinese: Has it changed?" Journal of Pragmatics, vol. 42, no. 7, pp. 1951-1963, 2010.

[16] R. Chen, "Compliment and compliment response research: A cross-cultural survey," Pragmatics Across Languages and Cultures, pp. 79-102, 2010.

[17] Z. Ye, How to Compliment and Respond to People in English, Beijing: Chinese Textile Press, 2011.

[18] R. Wu, "Attitudes towards compliment responses," Journal of Heilongjiang College, vol. 11, no. 3, pp. 101-109, 2012.

[19] R. Chen, "Responding to compliments: A contrastive study of politeness strategies between American English and Chinese speakers," Journal of Pragmatics, vol. 20, no. 1, pp. 49-75, 1993.

[20] K. P. Schneider and I. Schneider, "Bescheidenheit in vier Kulturen: Komplimenterwiderungen in den USA, Irland, Deutschland und China," Ethische Konzepte und Mentale Kulturen, vol. 2, pp. 65-80, 2000 .

[21] T. Loh, "Responses to compliments across cultures: A comparative study of British and Hong Kong Chinese," M.S. thesis, Department of English, Hong Kong City Poly Technique Univ., 1993.

[22] Y. Yuan, "An inquiry into empirical pragmatics data-gathering methods: Written DCTs, oral DCTs, field notes, and natural conversations," Journal of Pragmatics, vol. 33, no. 2, pp. 271-292, 2001.

[23] Y. Yuan, "Compliments and compliment responses in Kunming Chinese," Journal of Pragmatics, vol. 12, no. 2, pp. 62-68, 2002.

[24] M. C. Yu, "Interlinguistic variation and similarity in second language speech act behavior," The Modern Language Journal, vol. 88, no. 1, pp. 102-119, 2004.

Copyright (C) 2020 by the authors. This is an open access article distributed under the Creative Commons Attribution License which permits unrestricted use, distribution, and reproduction in any medium, provided the original work is properly cited (CC BY 4.0). 


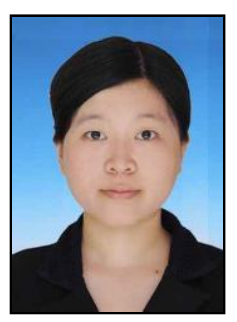

Fan Yang was born in China in 1992. She got her master degree at the Chinese University of Hong Kong and her bachelor degree at Beijing Normal University. Her major field of study is second language teaching and second language acquisition.

She is a lecturer in Glasgow College, University of Electronic Science and Technology of China. She had rich experience in the teaching practice of engineering English and English for academic purposes.

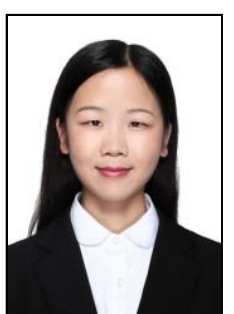

Shuyan He was born in China in 1988. She got her master degree at University of Electronic Science and Technology of China and her bachelor degree at Sichuan International Studies University. Her major field of study is translation and interpreting.

She is a lecturer in University of Electronic Science and Technology of China. She had rich experience in the teaching practice of English for academic purposes.

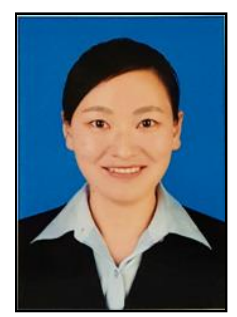

Linyi Qi was born in China in 1986. She got her master degree and bachelor degree at Sichuan University. Her major field of study is English literature.

She is the co-lead and lecturer in Glasgow College, University of Electronic Science and Technology of China. She had rich experience in the teaching practice of English reading and English for academic purposes.

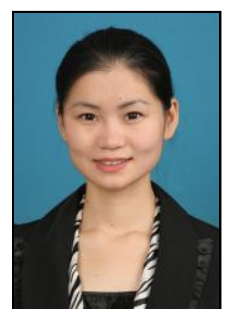

Jing Wen was born in China in 1987. She got her master degree at Tianjin Foreign Studies University and her bachelor degree at Harbin Institute of Technology. Her major field of study is applied linguistics.

She is a lecturer in University of Electronic Science and Technology of China with rich experience in the teaching practice of engineering English and English writing. 